\title{
Pengaruh Comprehensive Stakeholder Pressure dan Good Corporate Governance terhadap Kualitas Sustainability Report
}

\author{
Sriningsih $^{1 *}$, Indah Fajarini Sri Wahyuningrum² \\ Universitas Negeri Semarang ${ }^{1,2}$ \\ ningsihsri795@gmail.com ${ }^{1}$, i.fajarini@mail.unnes.ac.id ${ }^{2}$
}

\author{
*Penulis Korespondensi \\ Diajukan : 20 Desember 2021 \\ Disetujui : 16 Januari 2022 \\ Dipublikasi : 19 Januari 2022
}

\begin{abstract}
This study aims to analyze the effect of comprehensive stakeholder pressure and good corporate governance (GCG) on sustainability report quality. The population in this study are companies listed on the Indonesia Stock Exchange (IDX) in 2017-2019 period. The technique used is purposive sampling, in order to obtain a sample of 138 units of analysis. The data was collected using documentation method. The data was analyzed using descriptive statistical analysis and multiple linear regression analysis with SPSS. The results showed that industries close to consumers, environmentally sensitive industries, and media exposure had a significant positive effect on sustainability report quality. The audit by KAP Big 4 and the effectiveness of the Board of Commissioners have a significant negative effect on sustainability report quality. Meanwhile, investor-oriented industry, employee-oriented industry, creditor pressure, government pressure, and the Audit Committee have no influence on sustainability report quality. Based on the research results, government is expected to be able to clarify regulations regarding the disclosure of the sustainability report and encourage the disclosure of GRI sectoral content in the sustainability report. Further research is expected to use the scoring method to measure the quality of the sustainability report and other proxies to measure the effect of stakeholder pressure on the quality of the sustainability report.
\end{abstract}

Keywords : Sustainability Report Quality; Stakeholder Pressure; Board of Commissioner; Audit Committee.

\section{PENDAHULUAN}

Pendirian perusahaan memiliki tujuan untuk memaksimalkan perolehan keuntungan atau laba, namun perusahaan diharuskan tidak hanya memprioritaskan aspek ekonomi, melainkan juga aspek sosial dan lingkungan. John Elkington pada 1994 mengemukakan bahwa perusahaan yang berkelanjutan seharusnya mengorientasikan keuntungan (profit), menyejahterakan masyarakat umum termasuk karyawan (people), serta menjaga kondisi lingkungan hidup (planet). Akan tetapi, kenyataannya menunjukkan bahwa terdapat 302 masalah lingkungan hidup maupun agraria terjadi selama tahun 2017 menurut survei Wahana Lingkungan Hidup Indonesia (WALHI). Catatan Konsorsium Pembaruan Agraria sepanjang tahun 2020 juga mencatat 106 kasus konflik agraria berkaitan dengan perusahaan swasta dan 12 kasus antara BUMN dengan masyarakat. Permasalahan tersebut memperlihatkan lemahnya kepedulian perusahaan terhadap lingkungan maupun masyarakat sekitar sehingga muncul berbagai tuntutan dari stakeholder atas informasi yang transparan mengenai aktivitas perusahaan. Laporan keuangan yang diterbitkan perusahaan dinilai tidak lagi cukup untuk mengetahui apakah keadaan lingkungan dan sosial telah dijaga oleh perusahaan, sehingga 
dibutuhkan laporan non keuangan (Sari \& Nurkhin, 2020). Laporan non keuangan terangkum dalam konsep keberlanjutan dikenal sebagai sustainability report (laporan keberlanjutan).

Keberadaan sustainability report sangat krusial. Pengungkapan sustainability report bagi perusahaan finansial (keuangan), emiten, dan perusahaan publik telah wajib dilakukan (POJK Nomor 51/POJK. 03/2017, 2017). Akan tetapi, pengungkapan sustainability report di Indonesia saat ini masih terbilang rendah. Loh \& Thomas (2018), Center for Governance Institutions and Organization di National University of Singapure (NUS) Business School menunjukkan tingkat pengungkapan sustainability report di lima negara ASEAN yaitu Malaysia, Filipina, Thailand, Singapura, dan Indonesia. Posisi terendah pengungkapan sustainability report ditempati oleh Indonesia yaitu sebesar 53,6\% dibawah rata-rata negara di ASEAN. Sepanjang tahun 2017-2020 jumlah perusahaan publik yang listing di Bursa Efek Indonesia dengan penerbitan sustainability report secara stand alone (terpisah dari annual report) tidak menunjukkan penambahan yang signifikan. Jumlah perusahaan tersebut hanya sebanyak $9 \%$ tahun $2017,8,7 \%$ tahun $2018,8,5 \%$ tahun 2019 , dan $6 \%$ pada tahun 2020 dari keseluruhan perusahaan yang sudah listing di BEI (lihat Tabel 1).

Tabel 1. Jumlah Perusahaan Terdaftar di Bursa Efek Indonesia yang Menerbitkan Sustainability Report Tahun 2017-2020

\begin{tabular}{lcccc}
\hline & $\mathbf{2 0 1 7}$ & $\mathbf{2 0 1 8}$ & $\mathbf{2 0 1 9}$ & $\mathbf{2 0 2 0}$ \\
\hline Perusahaan yang terdaftar di Bursa Efek Indonesia & 557 & 608 & 668 & 696 \\
Perusahaan yang tidak menerbitkan sustainability report & 506 & 555 & 611 & 655 \\
Perusahaan yang menerbitkan sustainability report & 51 & 53 & 57 & 41 \\
$(\%)$ & $9 \%$ & $8,7 \%$ & $8,5 \%$ & $6 \%$ \\
\hline
\end{tabular}

Sumber: Data diolah, 2021

Berdasarkan permasalahan mengenai sustainability report tersebut, penelitian ini tertarik untuk mempelajari kualitas sustainability report di Indonesia. Good corporate governance atau tata kelola perusahaan yang baik menjadi topik layak dikaji dalam meningkatkan kualitas sustainability report. Keberadaan Dewan Komisaris menjadi dimensi dalam good corporate governance yang dapat membantu perusahaan untuk meningkatkan kuantitas dan kualitas laporan sustainability report (Diono et al., 2017; Rudyanto \& Siregar, 2018). Sementara itu, Sulistyawati \& Qadratin (2018) dan Pratama \& Yulianto (2015) menemukan hasil berbeda yaitu keberadaan Dewan Komisaris tidak memberikan pengaruh terhadap pengungkapan maupun kualitas sustainability report. Komite Audit layak untuk diteliti sebagai komite yang oleh dan bertanggungjawab kepada Dewan Komisaris serta berperan mengarahkan manajemen dalam publikasi sustainability report. Pernyataan tersebut didukung hasil penelitian dari Aniktia \& Khafid (2015) dan Natalia \& Wahidahwati (2016) bahwa Komite Audit berpengaruh positif signifikan terhadap kualitas sustainability report. Madona \& Khafid (2019) menemukan hasil berbeda berupa Komite Audit tidak berpengaruh terhadap sustainability report.

Perkembangan bisnis modern mendorong pengaruh tekanan sustainability report tidak hanya berada pada lingkup pemangku kepentingan utama. Stakeholder dapat berasal dari berbagai lini bisnis dan operasional perusahaan. Buysse \& Verbeke (2003) mengkategorikan stakeholder menjadi empat kelompok antara lain internal primary stakeholder, external primary stakeholder, secondary stakeholder, dan regulatory stakeholder. Klasifikasi tersebut diharapkan mampu memfasilitasi kesimpulan yang komprehensif dibandingkan penelitian sebelumnya karena stakeholder akan memberikan dorongan yang berbeda dalam pengungkapan sustainability report (Trianaputri \& Djakman, 2019).

Berdasarkan uraian di atas, penelitian ini bertujuan menganalisis pengaruh atribut good corporate governance yang terdiri dari Efektivitas Dewan Komisaris dan Komite Audit serta 
comprehensive stakeholder pressure terhadap kualitas sustainability report. Orisinalitas penelitian ini yaitu mengkombinasikan beberapa variabel tekanan stakeholder yang diduga mampu mempengaruhi kualitas sustainability report. Dimensi-dimensi tekanan stakeholder pada penelitian ini berasal dari penelitian-penelitian sebelumnya dan pengkategorian yang dilakukan oleh Buysse \& Verbeke (2003). Empat kelompok stakeholder tersebut antara lain internal primary stakeholder (industri berorientasi investor \& industri berorientasi karyawan), external primary stakeholder (industri dekat konsumen, industri sensitif lingkungan \& tekanan kreditur), secondary stakeholder (eksposur media \& audit oleh KAP Big 4) dan regulatory stakeholder (tekanan pemerintah).

\section{STUDI LITERATUR}

Stakeholder theory, legitimacy theory, agency theory, dan media agenda setting theory menjadi grand theory dalam penelitian ini. Freeman (1984) mendefinisikan istilah stakeholder sebagai kelompok atau individu yang mampu memberikan dukungan terhadap tujuan organisasi, berpengaruh dan dipengaruhi oleh organisasi. Deegan (2004) menjelaskan stakeholder theory sebagai teori yang mendasari bahwa setiap stakeholder memiliki hak atas informasi terkait aktivitas perusahaan yang dapat dipakai dan mempengaruhi pengambilan keputusan mereka. Pencapaian tujuan keuangan dapat berupa laba perusahaan yang tinggi, sedangkan tujuan non-keuangan seperti pelaksanaan program tanggung jawab sosial dan lingkungan. Dowling \& Pfeffer (1975) melalui legitimacy theory menegaskan bahwa organisasi menganggap legitimasi sebagai hal penting, pedoman dan batasan yang muncul dari norma dan nilai sosial, serta reaksi terhadap pedoman maupun batasan tersebut mendorong adanya analisis perilaku organisasi/perusahaan dalam memperhatikan lingkungan. Teori legitimasi menegaskan bahwa setiap perusahaan akan terus-menerus berupaya untuk menyesuaikan diri dalam operasi perusahaannya dengan norma yang berlaku dan ada dalam lingkungan masyarakat dimana perusahaan bersebut berdiri. Sama dengan hubungan prinsipalagen dalam agency theory, kontrak antara prinsipal sebagai pemangku kepentingan yang melibatkan perusahaan sebagai agen, untuk mendelegasikan dalam pengambilan keputusankeputusan yang baik bagi kepentingan prinsipal (Jensen \& Meckling, 1976). Adanya asimetri informasi mengharuskan pemegang saham harus mengawasi manajemen dengan berbagai cara untuk meyakini bahwa manajemen bertindak sesuai dengan kepentingan pemegang saham seperti adanya tata kelola perusahaan yang efektif (Rudyanto \& Siregar, 2018). Media agenda setting theory dikemukakan pertama kali oleh McCombs dan Shaw (1972) yang menemukan fakta bahwa liputan berita dari media pers Amerika Serikat mampu menentukan opini publik dalam Pemilu Presiden Amerika Serikat tahun 1968. Brown \& Deegan (1998) menjelaskan bahwa media tidak hanya dilihat sebagai cerminan atas opini publik, melainkan sebagai pembentuk atas opini. Seiring berkembangnya penelitian terhadap media agenda setting theory, penerapan terhadap teori ini tidak hanya merujuk pada bidang politik, tetapi juga dalam bidang komunikasi dan bisnis (Trianaputri \& Djakman, 2019). Peranan media dalam membentuk opini publik diduga juga mempengaruhi strategi perusahaan dalam mengungkapkan informasi lingkungan dalam laporan tahunan (Elijido-Ten, 2011).

\section{Pengaruh Industri Berorientasi Investor terhadap Kualitas Sustainability Report}

Internal primary stakeholder yang diuji dalam penelitian ini adalah pemegang saham (investor) dan karyawan. Industri yang memiliki jumlah investor dengan tingkat penyebaran kepemilikan saham yang tinggi dianggap sebagai industri berorientasi investor. Kerangka stakeholder theory memposisikan pemegang saham/investor sebagai stakeholder yang berhak atas manfaat dari perusahaan dalam berbagai bentuk informasi finansial maupun non-finansial. Investor memerlukan informasi lingkungan dan sosial khususnya berkaitan dalam pengambilan keputusan. Pemegang saham khususnya pemegang saham mayoritas (dominan) akan berupaya untuk memperoleh laporan sustainability report yang berkualitas melalui mekanisme 
pengawasan, baik secara langsung dalam RUPS (Rapat Umum Pemegang Saham) maupun tidak langsung. Oleh karena itu, semakin kuat tekanan investor akan diikuti oleh sustainability report perusahaan yang semakin berkualitas (Fernandez-Feijoo et al., 2014; Nilawati et al., 2019; Suharyani et al., 2019).

H1a: Industri berorientasi investor berpengaruh positif signifikan terhadap kualitas sustainability report.

\section{Pengaruh Industri Berorientasi Karyawan terhadap Kualitas Sustainability Report}

Karyawan adalah modal intelektual dan pelaksana strategi perusahaan, bertindak sebagai pemangku kepentingan utama. Sebagai internal primary stakeholder, karyawan juga memiliki harapan bahwa perusahaan dapat going concern dan tumbuh berkelanjutan untuk setidaknya memastikan perusahaan memprioritaskan kesejahteraan mereka. Karyawan saat ini memperhatikan apakah perusahaan bertanggung jawab atas kepentingan sosial dan lingkungan atau tidak (Rudyanto \& Siregar, 2018). Oleh karena itu, perusahaan dalam industri yang berorientasi karyawan akan mengungkapkan laporan keberlanjutan yang lebih transparan dan berkualitas (Fernandez-Feijoo et al., 2014; Mnif Sellami et al., 2019).

$\mathrm{H} 1 \mathrm{~b}$ : Industri berorientasi karyawan berpengaruh positif signifikan terhadap kualitas sustainability report.

\section{Pengaruh Industri Dekat Konsumen terhadap Kualitas Sustainability Report}

External primary stakeholder juga merupakan pemangku kepentingan utama yang mampu memberikan pengaruh bagi perusahaan termasuk terhadap kualitas sustainability report. Terdapat tiga kelompok pemangku kepetingan yang diuji dalam penelitian ini yaitu industri dekat konsumen, industri sensitif lingkungan, dan tekanan kreditur. Konsumen sebagai external primary stakeholder mampu memberikan pengaruh dalam penentuan kebijakan pengungkapan sustainability report pada sebuah perusahaan. Legitimacy theory menjelaskan bahwa setiap perusahaan akan berupaya untuk memastikan aktivitasnya mampu diterima oleh lingkungan dan masyarakat termasuk konsumen akhir. Perusahaan yang memiliki kedekatan dengan konsumen dinilai menerbitkan sustainability report yang lebih baik dibanding perusahaan yang tidak dekat konsumen (Alfaiz \& Aryati, 2019; Rudyanto \& Siregar, 2018; Sari \& Nurkhin, 2020).

H2a: Industri dekat konsumen berpengaruh positif signifikan terhadap kualitas sustainability report.

\section{Pengaruh Industri Sensitif Lingkungan terhadap Kualitas Sustainability Report}

Perusahaan dengan kecenderungan sensitif terhadap lingkungan seringkali mengungkapkan sustainability report yang lebih berkualitas untuk memperoleh legitimasi masyarakat atas aktivitas perusahaan. Perusahaan dengan keterkaitan lingkungan yang memadai akan memiliki lebih banyak peluang untuk memberikan tingkat pengungkapan lingkungan yang lebih tinggi (Wahyuningrum et al., 2020). Hal ini dikarenakan perusahaanperusahaan tersebut berpotensi memberikan dampak lingkungan yang besar. Semakin perusahaan sensitif terhadap lingkungan, maka kepentingan perusahaan untuk mengungkapkan sustainability report yang berkualitas akan semakin tinggi (Lulu, 2020; Rudyanto \& Siregar, 2018; Sari \& Nurkhin, 2020).

H2b: Industri sensitif lingkungan berpengaruh positif signifikan terhadap kualitas sustainability report.

\section{Pengaruh Tekanan Kreditur terhadap Kualitas Sustainability Report}

Kreditur sebagai pihak penyedia pinjaman merupakan pemangku kepentingan yang dapat mempengaruhi aktivitas dan tingkat pengungkapan informasi oleh perusahaan (Lu \& Abeysekera, 2014). Konsep stakeholder theory menjelaskan bahwa kreditur memiliki 
kekuasaan dan dapat memberikan tuntutan yang sah melalui pinjamannya. Perkembangan kebijakan kredit juga semakin mengarah ke sistem kredit hijau, dimana kreditur menjadikan informasi lingkungan perusahaan sebagai pertimbangan kredit. Oleh karena itu, untuk memastikan kondisi perusahaan, kreditur menuntut perusahaan untuk transparan dan mengungkapkan lebih banyak informasi, termasuk sustainability report yang berkualitas (Huang \& Kung, 2010; Lu \& Abeysekera, 2014).

H2c: Tekanan kreditur berpengaruh positif terhadap kualitas sustainability report.

\section{Pengaruh Eksposur Media terhadap Kualitas Sustainability Report}

Secondary stakeholder terbagi menjadi dua kelompok pemangku kepentingan untuk diuji dalam penelitian ini yaitu media massa dan auditor. Kerangka media agenda setting theory menjelaskan media tidak hanya dilihat sebagai cerminan atas opini publik, melainkan sebagai pembentuk atas opini tersebut. Eksposur/paparan media didefinisikan sebagai laporan oleh media massa yang menonjolkan perusahaan. Media menjadi dua mata pisau yang bertugas sebagai strategi untuk memperoleh legitimasi masyarakat sekaligus menjadi tekanan bagi perusahaan. Masyarakat/publik sebagai stakeholder dengan power melalui media dapat menekan perusahaan untuk transparan dalam pengungkapan keberlanjutan. Hal ini yang menjadikan perusahaan dengan liputan media yang lebih besar seringkali mengungkapkan sustainability report yang berkualitas (Rupley et al., 2012; Solikhah \& Maulina, 2021; Trianaputri \& Djakman, 2019).

$\mathrm{H} 3 \mathrm{a}$ : Eksposur media berpengaruh positif signifikan terhadap kualitas sustainability report.

\section{Pengaruh Audit oleh KAP Big 4 terhadap Kualitas Sustainability Report}

Auditor sebagai pihak independen dan professional, memilki peran dalam mempengaruhi dan mengarahkan klien mereka untuk memulai praktik akuntansi yang berkembang seperti pengungkapan sosial dan lingkungan. Auditor Big 4 mengharuskan klien mereka untuk meningkatkan tingkat pengungkapan sukarela termasuk laporan sustainability report untuk meningkatkan visibilitas perusahaan. Auditor Big 4 tersebut secara professional berpengaruh dalam membimbing perusahaan untuk memulai, mempromosikan dan menjamin assurance pada sustainability report yang diterbitkan perusahaan. Tekanan dari auditor menjadi alasan perusahaan untuk mempertimbangkan penerbitan sustainability report yang berkualitas (Lu \& Abeysekera, 2014; Trianaputri \& Djakman, 2019).

H3b: Audit oleh KAP Big 4 berpengaruh positif signifikan terhadap kualitas sustainability report.

\section{Pengaruh Tekanan Pemerintah terhadap Kualitas Sustainability Report}

Sebagai regulator, pemerintah termasuk stakeholder yang memiliki peran besar dalam menekan dan mempengaruhi aktivitas operasional perusahaan. Seperti yang dijelaskan dalam cabang manajerial stakeholder theory pemerintah dan badan pengatur lainnya memiliki atribut kekuasaan dengan menetapkan aturan yang harus dipatuhi oleh perusahaan dan atribut legitimasi dengan menetapkan norma dan standar praktik pelaporan keberlanjutan serta pedomannya (Dong \& Xu, 2016). Perusahaan yang mematuhi regulasi pemerintah cenderung tertib dalam menerbitkan pengungkapan laporan sustainability. Semakin kuat tekanan pemerintah, maka semakin berkualitas sustainability report yang diterbitkan perusahaan ( $\mathrm{He}$ et al., 2017; Lu \& Abeysekera, 2014).

H4: Tekanan Pemerintah berpengaruh positif signifikan terhadap kualitas sustainability report.

\section{Pengaruh Efektivitas Dewan Komisaris terhadap Kualitas Sustainability Report}

Stakeholder theory mengemukakan bahwa Dewan Komisaris yang efektif dapat memastikan manajemen perusahaan telah berperilaku sesuai dengan keinginan pemangku kepentingan termasuk terkait pengungkapan tanggung jawab ekonomi, sosial dan lingkungan. 
Efektivitas Dewan Komisaris akan menimbulkan sistem pelaporan yang lebih baik dan berimbas pada peningkatan pelaporan sukarela termasuk sustainability report. Hal ini menjadikan semakin efektif Dewan Komisaris, semakin berkualitas sustainability report yang dipublikasikan oleh perusahaan (Diono et al., 2017; Oktavianawati \& Wahyuningrum, 2019; Pratama \& Yulianto, 2015; Rudyanto \& Siregar, 2018).

H5: Efektivitas Dewan Komisaris berpengaruh positif signifikan terhadap kualitas sustainability report.

\section{Pengaruh Komite Audit terhadap Kualitas Sustainability Report}

Kerangka agency theory menyatakan bahwa Komite Audit berperan dalam membantu penyelesaian masalah asimetri informasi antara prinsipal dan agen. Komite Audit dalam mekanisme tata kelola perusahaan berperan membantu manajemen dalam mempublikasikan sustainability report. Komite Audit bertugas mengarahkan direksi dan manajemen terkait pelaporan tanggung jawab ekonomi, sosial, dan lingkungan dalam pengungkapan sustainability report. Komite Audit yang berintegritas akan mampu memahami makna strategis dari pengungkapan sustainability report sebagai alat komunikasi perusahaan dengan pemangku kepentingannya. Semakin efektif Komite Audit menjalankan tugasnya akan diikuti semakin berkualitasnya sustainability report perusahaan (Latifah et al., 2019; Natalia et al., 2016).

H6: Komite Audit berpengaruh positif signifikan terhadap kualitas sustainability report.

\section{Penelitian Terdahulu}

Lu \& Abeysekera (2014) meneliti pengaruh tekanan stakeholder dan karakteristik perusahaan terhadap pengungkapan sosial dan lingkungan perusahaan di China. Hasil penelitian menunjukkan ukuran perusahaan, profitabilitas dan tipe industri memiliki pengaruh positif signifikan terhadap pengungkapan sosial dan lingkungan. Karateristik perusahaan yang lain yaitu apakah perusahaan listing di bursa luar negeri tidak berpengaruh terhadap pengungkapan sosial dan lingkungan. Tekanan stakeholder berupa tekanan pemegang saham menunjukkan pengaruh negatif signifikan terhadap pengungkapan sosial dan lingkungan. Tekanan pemerintah, kreditur dan auditor tidak berpengaruh terhadap pengungkapan sosial dan lingkungan. Lucia \& Panggabean (2018) meneliti pengaruh karakteristik dan tata kelola perusahaan terhadap pengungkapan sustainability report pada perusahaan manufaktur yang listing di Bursa Efek Indonesia dan Bursa Malaysia pada tahun 2013 sampai 2015. Perusahaan dengan profitabilitas dan ukuran perusahaan yang besar memiliki pengungkapan sustainability report yang tinggi. Indikator lain seperti leverage, likuiditas, dan dewan direksi tidak berpengaruh terhadap pengungkapan sustainability report. Variabel terkait tata kelola perusahaan yaitu Komite Audit dinilai mengurangi tingkat pengungkapan sustainability report ditunjukkan dari hasil penelitian yang pengaruh negatif. Trianaputri \& Djakman (2019) melakukan penelitian pada perusahaan yang berada di negara ASEAN-5 (Indonesia, Malaysia, Singapura, Thailand, Filipina) khususnya pada 224 perusahaan sektor primer. Hasil penelitian menunjukkan bahwa tingkat intensitas tenaga kerja, eksposur media, perusahaan yang diaudit Big 4, kekuatan peraturan terkait CSR/sustainability memberikan pengaruh positif signifikan terhadap kualitas sustainability report. Variabel lain dalam penelitian yaitu kreditur mempengaruhi kualitas sustainability report secara negatif dan tingkat difusi pemegang saham tidak berpengaruh terhadap kualitas sustainability report.

\section{METODE}

Penelitian ini menggunakan metode kuantitatif dengan jenis data sekunder. Populasi penelitian merupakan perusahaan yang listing di Bursa Efek Indonesia tahun 2017-2019 pada semua sektor. Data penelitian sebanyak 138 unit yang diseleksi dengan teknik purposive sampling. Tabel 2 menjelaskan kriteria seleksi sampel penelitian sebagai berikut. 


\section{Kriteria}

Perusahaan yang konsisten terdaftar di BEI tahun 2017-2019 pada semua sektor

Perusahaan yang tidak menerbitkan sustainability report secara terpisah

Perusahaan yang tidak menerbitkan annual report selama tahun 2017-2019

Perusahaan dengan sustainability report tidak dapat diakses

Perusahaan yang menerbitkan sustainability report untuk satu grup

Perusahaan yang tidak menerbitkan sustainability report 3 (tiga) tahun berturut-

turut pada 2017-2019

Perusahaan yang tidak memiliki data lengkap lainnya yang terkait dengan variabel-variabel yang digunakan dalam penelitian

Total Sampel Perusahaan

Periode penelitian tahun 2017-2019

Total Unit Analisis
Jumlah

542

Sumber: Data diolah, 2021

Variabel penelitian masing-masing didefinisikan dalam Tabel 3. Pengumpulan data menggunakan studi dokumentasi berupa sustainability report dan laporan tahunan yang diperoleh dari situs perusahaan terkait maupun situs www.idx.co.id. Teknik analisis data menggunakan analisis statistik deskriptif, uji asumsi klasik, analisis regresi linear berganda, dan uji hipotesis dengan bantuan software IBM SPSS versi 25. Model persamaan regresi linier berganda digambarkan pada persamaan 1 .

KUAL_SR $=\alpha+\beta_{1}$ INVEST $+\beta_{2}$ EMPL $+\beta_{3}$ CONS $+\beta_{4}$ ENVI $+\beta_{5}$ CRED $+\beta_{6}$ MEDX + $\beta_{7}$ AUD $+\beta_{8}$ REG $+\beta_{9}$ DEKOM $+\beta_{10}$ KOM_AUD $+\beta_{11}$ SIZE $+\beta_{12}$ PROFIT + e.

Tabel 3. Definisi Operasional Variabel

\begin{tabular}{|c|c|c|}
\hline $\begin{array}{c}\text { Variabel/ } \\
\text { Simbol }\end{array}$ & Definisi Operasional & Pengukuran \\
\hline $\begin{array}{l}\text { Kualitas } \\
\text { Sustainabili } \\
\text { ty Report/ } \\
\text { KUAL_SR }\end{array}$ & $\begin{array}{l}\text { Kualitas laporan non-keuangan } \\
\text { yang berisi kondisi ekonomi, sosial, } \\
\text { dan lingkungan. } \\
\text { (Rudyanto \& Siregar, 2018) }\end{array}$ & $\begin{array}{l}\text { Logaritma natural jumlah halaman, } \\
\text { checklist item pengungkapan GRI G4 } \\
\text { (91 indikator) dan GRI Standards (77 } \\
\text { indikator). } \\
\qquad \text { SRDI }=\frac{\boldsymbol{K}}{\boldsymbol{N}} \\
\text { (Sari \& Nurkhin, 2020) }\end{array}$ \\
\hline $\begin{array}{l}\text { Industri } \\
\text { Berorientasi } \\
\text { Investor/ } \\
\text { INVEST }\end{array}$ & $\begin{array}{l}\text { Industri dengan investor sebagai } \\
\text { pihak yang mempengaruhi } \\
\text { perusahaan. } \\
\text { (Fernandez-Feijoo et al., 2014) }\end{array}$ & $\begin{array}{l}\text { Ownership Structure Consentration }= \\
\text { Jumlah saham yang dipegang } \\
\text { perusahaan induk/mayoritas } \\
\text { Total keseluruhan saham } \\
\text { (Rudyanto \& Siregar, 2018) }\end{array}$ \\
\hline $\begin{array}{l}\text { Industri } \\
\text { Berorientasi } \\
\text { Karyawan/ } \\
\text { EMPL }\end{array}$ & $\begin{array}{l}\text { Industri dengan karyawan sebagai } \\
\text { stakeholder sebagai pihak yang } \\
\text { mempengaruhi perusahaan. } \\
\text { (Fernandez-Feijoo et al., 2014) }\end{array}$ & $\begin{array}{l}\text { Rasio intensitas tenaga kerja }= \\
\text { Total biaya tenaga kerja } \\
\text { Total aset tetap } \\
(\text { Trianaputri \& Djakman, 2019) }\end{array}$ \\
\hline $\begin{array}{l}\text { Industri } \\
\text { Dekat } \\
\text { Konsumen/ } \\
\text { CONS }\end{array}$ & $\begin{array}{l}\text { Industri yang menjadikan konsumen } \\
\text { atau pelanggan sebagai stakeholder } \\
\text { utama. } \\
\text { (Fernandez-Feijoo et al., 2014) }\end{array}$ & $\begin{array}{l}\text { Skor } 1 \text { untuk industri barang konsumen } \\
\text { primer, keuangan, industri (tekstil, } \\
\text { garmen, alas kaki), infrastruktur (jasa } \\
\text { komersial), energi (perdagangan, } \\
\text { distribusi, utilitas), perdagangan jasa } \\
\text { (restoran, pariwisata, percetakan, }\end{array}$ \\
\hline
\end{tabular}




\begin{tabular}{|c|c|c|}
\hline & & $\begin{array}{l}\text { media/iklan), perusahaan investasi, } \\
\text { perdagangan eceran/ritel, kesehatan } \\
\text { properti, real estate (hotel, properti, } \\
\text { apartemen), transportasi \& logistik. } \\
\text { Skor 0 (nol) untuk industri lain. } \\
\text { (Fernandez-Feijoo et al., 2014; } \\
\text { Rudyanto \& Siregar, 2018) }\end{array}$ \\
\hline $\begin{array}{l}\text { Industri } \\
\text { Sensitif } \\
\text { Lingkungan } \\
\text { /ENVI }\end{array}$ & $\begin{array}{l}\text { Industri dengan lingkungan sebagai } \\
\text { stakeholder utama. } \\
\text { (Fernandez-Feijoo et al., 2014) }\end{array}$ & $\begin{array}{l}\text { ENVI }=\frac{\mathbf{K}}{\mathbf{N}} \\
\text { (Suharyani et al., 2019) }\end{array}$ \\
\hline $\begin{array}{l}\text { Tekanan } \\
\text { Kreditur/ } \\
\text { CRED }\end{array}$ & 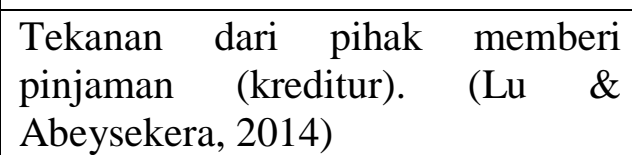 & $\begin{array}{r}\frac{\text { Total Liabilitas }}{\text { Total Aset }} \\
\text { (Lu \& Abeysekera, 2014) }\end{array}$ \\
\hline $\begin{array}{l}\text { Eksposur } \\
\text { Media/ } \\
\text { MEDX }\end{array}$ & $\begin{array}{l}\text { Laporan oleh media massa yang } \\
\text { menonjolkan perusahaan. } \\
\text { (Solikhah \& Maulina, 2021) }\end{array}$ & $\begin{array}{l}\text { Logaritma natural jumlah berita yang } \\
\text { terkait perusahaan di mesin pencari } \\
\text { Google dalam tahun pelaporan. } \\
\text { (Martínez-Ferrero et al., 2015) }\end{array}$ \\
\hline $\begin{array}{lr}\text { Audit } & \text { oleh } \\
\text { KAP } & \text { Big } \\
\text { 4/AUD } & \end{array}$ & $\begin{array}{l}\text { Auditor eksternal yang mengaudit } \\
\text { berasal dari Kantor Akuntan Publik } \\
\text { Big } 4 . \\
\text { (Lu \& Abeysekera, 2014) }\end{array}$ & $\begin{array}{l}\text { Skor } 1 \text { (satu) untuk perusahaan yang } \\
\text { diaudit oleh KAP Big } 4 \\
\text { (Pricewaterhouse Coopers, Deloitte } \\
\text { Touche Tohmatsu, KPMG, dan Ernest } \\
\text { and Young) dan skor 0 (nol) untuk } \\
\text { perusahaan yang diaudit oleh KAP non } \\
\text { Big 4. (Lu \& Abeysekera, 2014) }\end{array}$ \\
\hline $\begin{array}{l}\text { Tekanan } \\
\text { Pemerintah/ } \\
\text { REG }\end{array}$ & $\begin{array}{l}\text { Pemerintah dengan kewenangan } \\
\text { untuk menekan dan mempengaruhi } \\
\text { aktivitas operasional perusahaan. } \\
\text { (Lulu, 2020) }\end{array}$ & $\begin{array}{l}\text { Skor } 1 \text { (satu) pada perusahaan Badan } \\
\text { Usaha Milik Negara (BUMN) dan skor } \\
\text { (0) pada perusahaan yang tidak } \\
\text { termasuk BUMN. (Lulu, 2020) }\end{array}$ \\
\hline $\begin{array}{l}\text { Efektivitas } \\
\text { Dewan } \\
\text { Komisaris/ } \\
\text { DEKOM }\end{array}$ & $\begin{array}{l}\text { Dewan Komisaris melakukan } \\
\text { pengawasan umum dan/atau khusus } \\
\text { sesuai dengan anggaran dasar serta } \\
\text { memberi nasihat kepada direksi. } \\
\text { (UU No 40 Tahun 2007, 2007) }\end{array}$ & $\begin{array}{l}\text { Jumlah Anggota Dewan Komisaris. } \\
\text { (Pratama \& Yulianto, 2015) }\end{array}$ \\
\hline $\begin{array}{l}\text { Komite } \\
\text { Audit/ } \\
\text { KOM_AU } \\
\text { D }\end{array}$ & $\begin{array}{l}\text { Komite yang terdiri dari dan } \\
\text { bertanggung jawab kepada Dewan } \\
\text { Komisari, berperan membantu } \\
\text { pelaksanaan tugas maupun fungsi } \\
\text { Dewan Komisaris. (Sari \& Nurkhin, } \\
\text { 2020) }\end{array}$ & $\begin{array}{l}\text { Jumlah Anggota Komite Audit. } \\
\text { (Sari \& Nurkhin, 2020) }\end{array}$ \\
\hline $\begin{array}{l}\text { Ukuran } \\
\text { Perusahaan/ } \\
\text { SIZE }\end{array}$ & $\begin{array}{l}\text { Ukuran perusahaan pada periode } \\
\text { bersangkutan. (Aniktia \& Khafid, } \\
\text { 2015) }\end{array}$ & $\begin{array}{l}\text { Logaritma natural dari total aset. } \\
\text { (Rudyanto \& Siregar, 2018) }\end{array}$ \\
\hline $\begin{array}{l}\text { Profitabilita } \\
\text { S/ } \\
\text { PROFIT }\end{array}$ & $\begin{array}{llr}\text { Keuntungan } & \text { yang } & \text { diperoleh } \\
\text { perusahaan } & \text { selama } & \text { periode } \\
\text { pelaporan. (Sari \& Nurkhin, } & \text { 2020) }\end{array}$ & \begin{tabular}{|c|} 
Laba Bersih \\
Total Equity \\
(Rudyanto \& Siregar, 2018)
\end{tabular} \\
\hline
\end{tabular}

Sumber: Berbagai referensi, 2021 


\section{HASIL}

Pengujian statistik deskriptif digunakan sebagai gambaran persebaran variabel penelitian dan disajikan pada tabel 4. Pengujian menunjukkan variabel kualitas sustainability report, industri berorientasi investor, industri dekat konsumen, industri sensitif lingkungan, tekanan kreditur, eksposur media, audit oleh KAP Big 4, tekanan pemerintah, efektivitas Dewan Komisaris, Komite Audit, ukuran perusahaan dan profitabilitas memiliki distribusi data yang tergolong baik terlihat dari standar deviasi yang lebih kecil dari nilai rata-rata.

Tabel 4. Hasil Analisis Statistik Deskriptif

\begin{tabular}{|c|c|c|c|c|c|}
\hline & $\mathbf{N}$ & Min & Max & Mean & Std. Dev \\
\hline KUAL_SR & 138 & 3.63625 & 6.25771 & 5.1856362 & .47865737 \\
\hline INVEST & 138 & .10186 & .98307 & .5837186 & .17323116 \\
\hline EMPL & 138 & .01731 & 2.62222 & .4677724 & .49282508 \\
\hline CONS & 138 & 0 & 1 & .65 & .478 \\
\hline ENVI & 138 & .00000 & .80000 & .2381498 & .16444840 \\
\hline CRED & 138 & .12601 & .93650 & 6191407 & .22204297 \\
\hline MEDX & 138 & 3.25810 & 8.68440 & 5.8238625 & 1.22945595 \\
\hline AUD & 138 & 0 & 1 & .78 & .419 \\
\hline REG & 138 & 0 & 2 & .93 & .727 \\
\hline DEKOM & 138 & 3 & 12 & 6.40 & 1.798 \\
\hline KOM_AUD & 138 & 2 & 8 & 3.75 & 1.088 \\
\hline Valid N (listwise) & 138 & & & & \\
\hline
\end{tabular}

Sumber: Output SPSS, 2021

Uji statistik Kolmogorov-Smirnov menunjukkan nilai signifikansi sebesar 0,076 (>0.05) yang menandakan jika data penelitian terdistribusi normal. Nilai tolerance variabel $>0.1$ dan Variance Inflation Factor (VIF) sebesar >10, maka tidak terdapat gejala multikolinieritas antar variabel penelitian. Uji heteroskedastisitas menggunakan uji Park, hasilnya menunjukkan nilai signifikansi $>0.05$ pada tiap variabel penelitian, sehingga tidak terdapat heteroskedastisitas dalam model regresi ini. Uji Durbin-Waston digunakan dalam pengujian autokorelasi, hasilnya menunjukkan bahwa du $<\mathrm{d}<4$-du $(1.9134<1.918<2.0866)$ kesimpulannya penelitian ini terbebas dari gejala autokolerasi.

Koefisien determinasi (adjusted $R^{2)}$ sebesar 0.373 yang menandakan bahwa variabel terikat dipengaruhi oleh model penelitian sebesar $37.3 \%$ sedangkan sisanya atau $62.7 \%$ dipengaruhi oleh faktor eksternal. Persamaan regresi ditunjukkan oleh persamaan 2.

KUAL_SR $=2,119+0,131$ INVEST $-0,063$ EMPL $+0,213$ CONS + 1,226 ENVI $-0,57$ CRED + 0,108 MEDX - 0,231 AUD - 0,038 REG - 0,048 DEKOM + 0,042 KOM_AUD + 0,075 SIZE - 0,197 PROFIT + e

Kesimpulan hasil uji hipotesis penelitian terdapat pada tabel 5.

Tabel 5. Kesimpulan Hasil Uji Hipotesis

\begin{tabular}{|c|c|l|c|c|c|}
\hline \multicolumn{2}{|c|}{ Hipotesis } & $\boldsymbol{\beta}$ & Sig. & Hasil \\
\hline $\mathrm{H}_{1}$ & a & $\begin{array}{l}\text { Industri berorientasi investor berpengaruh positif } \\
\text { signifikan terhadap kualitas sustainability report }\end{array}$ & 0.131 & 0.525 & Ditolak \\
\cline { 2 - 6 } & b & $\begin{array}{l}\text { Industri berorientasi karyawan berpengaruh positif } \\
\text { signifikan terhadap kualitas sustainability report }\end{array}$ & -0.063 & 0.425 & Ditolak \\
\hline $\mathrm{H}_{2}$ & a & $\begin{array}{l}\text { Industri dekat konsumen berpengaruh positif } \\
\text { signifikan terhadap kualitas sustainability report }\end{array}$ & 0.213 & 0.027 & Diterima \\
\hline
\end{tabular}




\begin{tabular}{|c|c|l|c|c|c|}
\hline & b & $\begin{array}{l}\text { Industri sensitif lingkungan berpengaruh positif } \\
\text { signifikan terhadap kualitas sustainability report }\end{array}$ & 1.226 & 0.000 & Diterima \\
\cline { 2 - 6 } & c & $\begin{array}{l}\text { Tekanan kreditur berpengaruh positif terhadap kualitas } \\
\text { sustainability report }\end{array}$ & -0.057 & 0.804 & Ditolak \\
\hline \multirow{2}{*}{$\mathrm{H}_{3}$} & a & $\begin{array}{l}\text { Eksposur media berpengaruh positif signifikan } \\
\text { terhadap kualitas sustainability report }\end{array}$ & 0.108 & 0.002 & Diterima \\
\hline & $\begin{array}{l}\text { Audit oleh KAP Big 4 berpengaruh positif signifikan } \\
\text { terhadap kualitas sustainability report }\end{array}$ & -0.231 & 0,023 & Ditolak \\
\hline $\mathrm{H}_{4}$ & $\begin{array}{l}\text { Tekanan Pemerintah berpengaruh positif signifikan } \\
\text { terhadap kualitas sustainability report }\end{array}$ & -0.038 & 0,687 & Ditolak \\
\hline $\mathrm{H}_{5}$ & $\begin{array}{l}\text { Efektivitas Dewan Komisaris berpengaruh positif } \\
\text { signifikan terhadap kualitas sustainability report }\end{array}$ & -0.048 & 0,033 & Ditolak \\
\hline $\mathrm{H}_{6}$ & $\begin{array}{l}\text { Komite Audit berpengaruh positif signifikan terhadap } \\
\text { kualitas sustainability report }\end{array}$ & 0.042 & 0,291 & Ditolak \\
\hline
\end{tabular}

Sumber: Data sekunder diolah, 2021

\section{PEMBAHASAN \\ Pengaruh Industri Berorientasi Investor terhadap Kualitas Sustainability Report}

Industri berorientasi investor tidak memiliki pengaruh signifikan terhadap kualitas sustainability report. Tingkat konsentrasi kepemilikan saham mayoritas yang tinggi tidak membuat perusahaan menghasilkan laporan keberlanjutan yang berkualitas. Lulu (2020) mengungkapkan bahwa perusahaan induk sebagai pemegang saham mayoritas tidak menggunakan haknya untuk memantau dan mengontrol kinerja manajemen perusahaan dalam upaya pengungkapan keberlangsungan perusahaan pada sustainability report. Perhatian investor lebih berpusat pada informasi profit perusahaan tanpa memperhatikan prosedur yang dipakai untuk menghasilkan profit tersebut (Sari \& Nurkhin, 2020). Selaras dengan penelitian sebelumnya oleh Rudyanto \& Siregar (2018), Sari \& Nurkhin (2020).

\section{Pengaruh Industri Berorientasi Karyawan terhadap Kualitas Sustainability Report}

Industri berorientasi karyawan tidak memberikan pengaruh terhadap kualitas sustainability report perusahaan yang listing di Bursa Efek Indonesia. Rudiyanto \& Siregar (2018) mengungkapkan bahwa pengungkapan sustainability report cenderung dilihat oleh karyawan di Indonesia sebagai hal yang merugikan bagi perusahaan dan mengurangi nilai perusahaan. Pernyataan tersebut didukung oleh Ceil (2012) bahwa karyawan melihat pengungkapan sustainability report oleh perusahaan akan meningkatkan beban perusahaan dan dapat berakibat pada pengurangan gaji. Selaras dengan penelitian yang dilakukan oleh Lulu (2020), Sari \& Nurkhin (2020), Michael \& Lukman (2019), namun berlawanan dengan penelitian Fernandez-Feijoo et al (2014) dan Alfaiz \& Aryati (2019).

Hasil penelitian menunjukkan variabel industri berorientasi investor maupun variabel industri berorientasi karyawan tidak memiliki pengaruh terhadap kualitas sustainability report. Dengan demikian, internal primary stakeholder tidak memiliki berpengaruh terhadap kualitas sustainability report baik secara parsial maupun menyeluruh.

\section{Pengaruh Industri Dekat Konsumen terhadap Kualitas Sustainability Report}

Industri dekat konsumen memiliki pengaruh positif signifikan terhadap kualitas sustainability report. Konsumen tidak hanya menghabiskan uangnya untuk memperoleh barang/jasa yang terjangkau, tetapi juga cenderung menaruh prioritas pada apakah bahan produk tersebut ramah lingkungan, tidak adanya pelanggaran hak karyawan oleh perusahaan, serta pertimbangan terkait keberlanjutan lainnya. Perusahaan yang memiliki hubungan dekat konsumen akan diikuti visibilitas sosial yang tinggi, sehingga lebih mempertimbangkan isuisu penting keterlibatan masyarakat dalam kegiatan pengungkapan sustainability report oleh 
perusahaan. Perusahaan yang dekat konsumen juga berupaya mengungkapkan informasi tersebut ke dalam sustainability report untuk meningkatkan reputasi merek di mata masyarakat. Sejalan dengan penelitian yang dilakukan oleh Rudyanto \& Siregar (2018), Alfaiz \& Aryati (2019), Lulu (2020), Fernandez Feijoo et al. (2014).

\section{Pengaruh Industri Sensitif Lingkungan terhadap Kualitas Sustainability Report}

Industri sensitif lingkungan memiliki pengaruh positif signifikan terhadap kualitas sustainability report. Kerangka legitimacy theory menjelaskan bahwa masyarakat akan selalu mengawasi perusahaan agar bertindak sesuai dengan cara yang dapat diterima terutama perusahaan menjalankan operasionalnya agar tidak berdampak merusak lingkungan. Sebagai bentuk upaya mengurangi risiko dan tuduhan yang diarahkan kepada perusahaan dan agar tercipta hubungan yang saling harmonis antara perusahaan, masyarakat, dan lingkungannya, perusahaan harus melaksanakan kegiatan tanggung jawab sosial dan lingkungan serta melaporkannya melalui sustainability report yang berkualitas. Semakin luas dan detail pengungkapan sektor lingkungan perusahaan, maka semakin berkualitas sustainability report yang diterbitkan perusahan. Penelitian ini sejalan dengan penelitian Rudyanto \& Siregar (2018), Lulu (2020), Mnif Sellami et al (2019), Nilawati et al (2018).

\section{Pengaruh Tekanan Kreditur terhadap Kualitas Sustainability Report}

Tekanan kreditur tidak memiliki pengaruh terhadap kualitas sustainability report. Trianaputri \& Djakman (2019) menjelaskan bahwa perusahaan yang memiliki rasio hutang atas aset yang tinggi menunjukkan adanya ketidaksehatan keuangan perusahaan. Semakin tinggi rasio hutang perusahaan akan menyebabkan semakin besarnya alokasi biaya untuk membayar hutang berbasis bunga. Hal ini dapat menjadi salah satu alasan perusahaan untuk tidak mengalokasikan dana yang cukup agar menerbitkan sustainability report yang berkualitas (Trianaputri \& Djakman, 2019). Kreditur juga menganggap kewajiban perusahaan publik di Bursa Efek Indonesia untuk mengungkapkan sustainability report akan membebani perusahaan. Lulu (2020) mengungkapkan bahwa kreditur tidak memiliki kepedulian tentang seberapa berkualitas informasi yang diungkapkan dalam sustainability report ketika memberikan pinjaman kepada perusahaan.

Terdapat 2 dari 3 pemangku kepentingan eksternal utama (external primary stakeholder) yang berpengaruh terhadap kualitas sustainability report. Pemangku kepentingan eksternal utama (external primary stakeholder) memiliki pengaruh secara parsial terhadap kualitas sustainability report.

\section{Pengaruh Eksposur Media terhadap Kualitas Sustainability Report}

Eksposur media memiliki pengaruh terhadap kualitas sustainability report. Solikhah \& Maulina (2021) mengemukakan bahwa liputan media mampu meningkatkan perhatian atas masalah lingkungan. Ketika perusahaan dalam pengawasan publik, perusahaan akan merespon dengan membuat sustainability report yang berkualitas. Sustainability report yang disampaikan oleh perusahaan kepada stakeholder melalui berbagai media akan meyakinkan publik bahwa mereka beroperasi sesuai dengan harapan sosial dan untuk mendapatkan legitimasi sosial. Liputan media sebagai bagian dari secondary stakeholder akan menilai kinerja perusahaan berdasarkan kinerja ekonomi/keuangan perusahaan dan isu-isu yang dibawa oleh liputan media. Adanya ekposur media tersebut mendorong perusahaan untuk melakukan pengungkapan sustainability report yang lebih luas. Hasil penelitian ini sejalan dengan penelitian yang dilakukan oleh Trianaputri \& Djakman (2019), Solikhah \& Maulina (2021), Rupley et al. (2012). 


\section{Pengaruh Audit oleh KAP Big 4 terhadap Kualitas Sustainability Report}

Audit oleh KAP Big 4 memberikan pengaruh negatif signifikan terhadap kualitas sustainability report. Audit oleh KAP Big 4 justru menurunkan kualitas sustainability report. Hal tersebut mungkin terjadi ketika auditor Big 4 hanya dilibatkan oleh perusahaan dalam mengaudit laporan keuangan dan laporan tahunan perusahaan, namun tidak dengan sustainability report. Kecilnya pengaruh auditor menjadikan auditor eksternal umumnya tidak meminta atau mewajibkan atau mengamanatkan klien mereka untuk mengungkapkan informasi yang melebihi informasi yang disyaratkan oleh standar akuntansi (Soliman, 2013). Hasil ini tidak selaras dengan penelitian yang dilakukan oleh (Alkayed, 2018; Suttipun, 2014) yang menyatakan bahwa perlibatan KAP Big 4 dalam audit perusahaan memiliki pengaruh yang positif terhadap kualitas pengungkapan tanggung jawab sosial dan lingkungan dalam sustainability report.

Kedua pemangku kepentingan sekunder (secondary stakeholder) yang berpengaruh, meski memiliki arah yang berlawanan. Dengan demikian, pemangku kepentingan sekunder (secondary stakeholder) memiliki pengaruh secara penuh terhadap kualitas sustainability report.

\section{Pengaruh Tekanan Pemerintah terhadap Kualitas Sustainability Report}

Tekanan pemerintah tidak memiliki pengaruh terhadap kualitas sustainability report. Meskipun perusahaan BUMN dimiliki pemerintah atau secara tidak langsung dimiliki oleh masyarakat, tekanan pemerintah yang kuat tersebut tidak mendasari perusahaan BUMN menyajikan sustainability report yang berkualitas. Lulu (2020) mengemukakan bahwa terdapat ketidakkonsistenan dan kurang jelasnya sanksi hukum dalam beberapa undangundang, peraturan pemerintah, atau peraturan lembaga terkait yang menjadi dasar pengungkapan keberlanjutan. Permasalahan tersebut menjadi celah bagi perusahaan untuk tidak melaksanakan dan mengungkapkan sustainability report. Perusahaan bahkan hanya melaksanakan dan mengungkapkan sustainability report seadanya atau tidak sebagaimana mestinya. Hasil penelitian ini selaras dengan penelitian yang dilakukan oleh Lulu (2020) dan berlawanan dengan penelitian yang dilakukan oleh Lu \& Abeysekera (2014).

\section{Pengaruh Efektivitas Dewan Komisaris terhadap Kualitas Sustainability Report}

Efektivitas Dewan Komisaris memiliki pengaruh negatif secara signifikan terhadap kualitas sustainability report. Ukuran Dewan Komisaris yang kecil dinilai lebih efektif dalam memberikan pengawasan terhadap operasional perusahaan khususnya dalam pengungkapan sustainability report. Sebaliknya, Dewan Komisaris yang besar akan menyebabkan dominasi anggota untuk memprioritaskan kepentingan pribadi/kelompoknya daripada kepentingan perusahaan, sehingga kinerja Dewan Komisaris menjadi tidak efektif. Dewan Komisaris seharusnya dibentuk dengan mempertimbangkan komposisi, kapabilitas, dan integritas anggota agar mampu melaksanakan fungsi Dewan Komisaris yang efektif yaitu pengawasan, pengendalian dan memberikan masukan yang kredibel untuk kepentingan perusahaan. Hasil penelitian ini berlawanan dengan penelitian yang dilakukan oleh Rudyanto \& Siregar (2018) dan didukung oleh Mukti \& Kurnia (2015) \& Nur \& Priantinah (2012).

\section{Pengaruh Komite Audit terhadap Kualitas Sustainability Report}

Komite Audit tidak memiliki pengaruh terhadap kualitas sustainability report. Meski perusahaan memiliki jumlah Komite Audit yang besar, namun tidak diikuti oleh rapat yang dengan efektif. Kondisi tersebut menyebabkan Komite Audit didominasi oleh suara anggota yang mementingkan pribadi atau kelompoknya sehingga tidak memprioritaskan kepentingan perusahaan. Faktor lain yaitu belum adanya kepedulian Komite Audit dalam mengarahkan manajemen untuk mempublikasikan pengungkapan sustainability report yang berkualitas. Komite Audit tidak sungguh-sungguh dalam memberikan peran dalam penyusunan 
sustainability report yang berkualitas. Pengungkapan sustainability report hanya dipublikasikan sebagai penggugur kewajiban semata sehingga kualitas tidak menjadi objek penting yang dikaji Komite Audit melalui perannya dalam perusahaan. Hasil penelitian ini sejalan dengan penelitian yang dilakukan oleh Madona \& Khafid (2020), Pratama \& Yulianto, (2015).

\section{KESIMPULAN}

Penelitian ini membuktikan bahwa perusahaan yang berada dalam industri sensitif lingkungan, industri dekat konsumen maupun visibilitas/eksposur media yang besar memiliki kualitas sustainability report yang tinggi. Terdapat pengaruh negatif signifikan antara audit oleh KAP Big 4 dan Efektivitas Dewan Komisaris terhadap kualitas sustainability report. Perusahaan yang di audit oleh KAP Big 4 atau memiliki Dewan Komisaris dengan jumlah besar memiliki kualitas sustainability report yang rendah. Sementara itu, industri berorientasi investor, industri berorientasi karyawan, tekanan kreditur, tekanan pemerintah, dan Komite Audit tidak memiliki pengaruh terhadap kualitas sustainability report. Pemerintah diharapkan dapat memperjelas peraturan terkait pengungkapan laporan keberlanjutan dan mendorong pengungkapan konten sektoral GRI dalam sustainability report. Perusahaan diharapkan meningkatkan penerbitan sustainability report dan melibatkan auditor eksternal dalam assurance atas kualitasnya sebagai strategi marketing. Penelitian selanjutnya disarankan menggunakan pengukuran kualitas sustainability report yang menggunakan metode skoring semi objektif yang dibuat oleh berbagai peneliti agar dapat mengurangi subjektivitas penelitian. Peneliti selanjutnya dapat memakai proksi lain dalam mengukur industri sensitif lingkungan agar tidak terjadi pengukuran ganda pada penelitian.

\section{DAFTAR PUSTAKA}

Alfaiz, D. R., \& Aryati, T. (2019). Pengaruh Tekanan Stakeholder dan Kinerja Keuangan terhadap Kualitas Sustainability Report dengan Komite Audit sebagai Variabel Moderasi. Jurnal Akuntansi Dan Keuangan Methodist, 2(2), 112-130.

Alkayed, H. A. M. (2018). The Determinants and Consequences of Corporate Social Responsibility Disclosure: the Case of Jordan. 1-224.

Aniktia, R., \& Khafid, M. (2015). Pengaruh Mekaniseme Good Corporate Governance dan Kinerja Keuangan terhadap Pengungkapan Sustainability Report. Accounting Analysis Journal, 4(3), 1-10. https://doi.org/10.15294/aaj.v4i3.8303

Diono, H., Jatmiko, T., \& Prabowo, W. (2017). Analisis Pengaruh Mekanisme Corporate Governance, Profitalbilitas, dan Ukuran Perusahaan terhadap Tingkat Pengungkapan Sustainability Report. Diponegoro Journal of Accounting, 6(3), 615-624.

Dong, S., \& Xu, L. (2016). The Impact of Explicit CSR Regulation: Evidence from China's Mining Firms. Journal of Applied Accounting Research.

Elijido-Ten, E. (2011). Media Coverage and Voluntary Environmental Disclosures: A Developing Country Exploratory Experiment. Accounting Forum, 35(3), 139-157. https://doi.org/10.1016/j.accfor.2011.06.003

Fernandez-Feijoo, B., Romero, S., \& Ruiz, S. (2014). Effect of Stakeholders' Pressure on Transparency of Sustainability Reports within the GRI Framework. Journal of Business Ethics, 122(1), 53-63. https://doi.org/10.1007/s10551-013-1748-5

He, X., Wada, Y., Wanders, N., \& Sheffield, J. (2017). Intensification of Hydrological Drought in California by Human Water Management. Geophysical Research Letters, 44(4), 17771785. https://doi.org/10.1002/2016GL071665

Huang, C. L., \& Kung, F. H. (2010). Drivers of Environmental Disclosure and Stakeholder Expectation: Evidence from Taiwan. Journal of Business Ethics, 96(3), 435-451. https://doi.org/10.1007/s10551-010-0476-3

Jensen, M. C., \& Meckling, W. H. (1976). Theory of the Firm: Managerial Behavior, Agency 
Costs and Ownership Structure. Journal of Financial Economics, 3(4), 305-360. https://doi.org/https://doi.org/10.1016/0304-405X(76)90026-X

Latifah, S. W., Rosyid, M. F., Purwanti, L., \& Oktavendi, T. W. (2019). Analysis of Good Corporate Governance, Financial Performance and Sustainability Report. Jurnal Reviu Akuntansi Dan Keuangan, 9(2), 200. https://doi.org/10.22219/jrak.v9i2.8902

Loh, L., \& Thomas, T. (2018). Sustainability Reporting in ASEAN Countries. In S. P. Lee, L. Lynda, M. Marya, T. Sharemine, \& T. P. T. Nguyen (Eds.), National University of Singapore (2018th ed.). Asean CSR Network.

Lu, Y., \& Abeysekera, I. (2014). Stakeholders Power , Corporate Characteristics and Social and Environmental Disclosure : Evidence from China. Cleaner Production, 64(1), 426436.

Lulu, C. L. (2020). Stakeholder Pressure and the Quality of Sustainability Report : Evidence From Indonesia. Journal of Accounting, Entrepreneurship and Financial Technology, 2(1), 39-53.

Madona, M. A., \& Khafid, M. (2020). Pengaruh Good Corporate Governance terhadap Pengungkapan Sustainability Report dengan Ukuran Perusahaan sebagai Pemoderasi. Jurnal Optimasi Sistem Industri, 19(1), 22. https://doi.org/10.25077/josi.v19.n1.p2232.2020

Martínez-Ferrero, J., Garcia-Sanchez, I. M., \& Cuadrado-Ballesteros, B. (2015). Effect of Financial Reporting Quality on Sustainability Information Disclosure. Corporate Social Responsibility and Environmental Management, 22(1), 45-64. https://doi.org/10.1002/csr.1330

Mnif Sellami, Y., Dammak Ben Hlima, N., \& Jarboui, A. (2019). An Empirical Investigation of Determinants of Sustainability Report Assurance in France. Journal of Financial Reporting and Accounting, 17(2), 320-342. https://doi.org/10.1108/JFRA-02-2018-0019

Mukti, A., \& Kurnia. (2015). Pengaruh Karakteristik Perusahaan dan Ukuran Dewan Komisaris terhadap Pengungkapan Corporate Social Responsibility. Jurnal Ilmu Dan Riset Akuntansi, 4(12), 1-17.

Natalia, O., Fahriza, R., \& Wahidahwati. (2016). Faktor-Faktor yang Mempengaruhi Tingkat Pengungkapan Sustainability Report. Jurnal Ilmu Dan Riset Akuntansi, 5(November).

Nilawati, Y. J., Purwanti, E., \& Nuryaman, F. A. (2019). the Effect of Stakeholders' Pressure and Corporate Financial Performance on Transparency of Sustainability Report. Jurnal Akuntansi Trisakti, 5(2), 225. https://doi.org/10.25105/jat.v5i2.4867

Nur, M., \& Priantinah, D. (2012). Analisis Faktor-Faktor yang Mempengaruhi Pengungkapan CSR di Indonesia (Studi Empiris pada Perusahaan Berkategori High Profile yang Listing di BEI). Jurnal Nominal, I(I), 1-13.

Nurumina, A. T., Setiawa, R., Ramadhaniar, M. A., Hazazi, F. S. A. L., \& Sherlita, E. (2020). The Influence of Stakeholder Pressure and Corporate Governance on Sustainability Report Quality. PalArch's Journal of Archaeology of Egypt/Egyptology, 17(4), 27492765.

Oktavianawati, L., \& Wahyuningrum, I. F. S. (2019). Factors Affecting Corporate Social Responsibility (CSR) Disclosure. Accounting Analysis Journal, 8(2), 110-117.

POJK Nomor 51/POJK. 03/2017. (2017). Penerapan Keuangan Berkelanjutan Bagi Lembaga Jasa Keuangan, Emiten, dan Perusahaan Publik. Otoritas Jasa Keuangan.

Pratama, A., \& Yulianto, A. (2015). Faktor Keuangan dan Corporate Governance. Accounting Analysis Journal, 4(2), 1-10.

Rudyanto, A., \& Siregar, S. V. (2018). The effect of stakeholder pressure and corporate governance on the sustainability report quality. International Journal of Ethics and Systems, 34(2), 233-249. https://doi.org/10.1108/IJOES-05-2017-0071

Rupley, K. H., Brown, D., \& Marshall, R. S. (2012). Governance, Media and the Quality of 
Environmental Disclosure. Journal of Accounting and Public Policy, 31(6), 610-640. https://doi.org/https://doi.org/10.1016/j.jaccpubpol.2012.09.002

Sari, P. N., \& Nurkhin, A. (2020). Determinan Kualitas Sustainability Report Perusahaan LQ45 Tahun 2017 dan 2018. Economic Education Analysis Journal, 3(1).

Solikhah, B., \& Maulina, U. (2021). Factors Influencing Environment Disclosure Quality and the Moderating Role of Corporate Governance. Cogent Business \& Management, 8(1), 1876543. https://doi.org/10.1080/23311975.2021.1876543

Suharyani, R., Ulum, I., \& Jati, A. W. (2019). Pengaruh Tekanan Stakeholder dan Corporate Governance terhadap Kualitas Sustainability Report. Jurnal Akademi Akuntansi (JAA), 2(1).

Suttipun, M. (2014). Corporate Characteristics, Social Responsibility Reporting, and Financial Performance: Evidence in Thailand. Corporate Ownership and Control, 12(1CONT9), 836-847. https://doi.org/10.22495/cocv12i1c9p7

Trianaputri, A. R., \& Djakman, C. D. (2019). Quality of Sustainability Disclosure Among the Asean-5 Countries and the Role of Stakeholders. Jurnal Akuntansi Dan Keuangan Indonesia, 16(2), 180-205. http://jaki.ui.ac.id/index.php/home/article/view/1072

UU No 40 Tahun 2007. (2007). Perseroan Terbatas. Otoritas Jasa Keuangan.

Wahyuningrum, I. F. S., Budihardjo, M. A., Muhammad, F. I., Djajadikerta, H. G., \& Trireksani, T. (2020). Do Environmental and Financial Performances Affect Environmental Disclosures? Evidence from Listed Companies in Indonesia. Entrepreneurship and Sustainability Issues, 8(2), 1047-1061. https://doi.org/10.9770/jesi.2020.8.2(63) 